\title{
Gustatory Sensing Mechanism Coding for Multiple Oviposition Stimulants in the Swallowtail Butterfly, Papilio Xuthus
}

\author{
Masasuke Ryuda, ${ }^{1}$ Delphine Calas-List, ${ }^{2}$ Ayumi Yamada, ${ }^{3}$ Frédéric Marion-Poll, ${ }^{2,4}$ Hiroshi Yoshikawa, ${ }^{1}$ \\ Teiichi Tanimura, ${ }^{5}$ and Katsuhisa Ozaki ${ }^{1}$ \\ ${ }^{1}$ JT Biohistory Research Hall, Takatsuki Osaka, 569-1125, Japan, ${ }^{2}$ Institut national de la recherche agronomique, UMR 1272, Physiologie de l'Insecte: \\ Signalisation et Communication, 78026 Versailles, France, ${ }^{3}$ Graduate School of Science, Osaka University, Toyonaka, Osaka, 560-0043, Japan, \\ ${ }^{4}$ AgroParisTech, Département Sciences de la Vie et Santé, 75231 Paris Cedex 05, France, and ${ }^{5}$ Department of Biology, Graduate School of Sciences, Kyushu \\ University, Hakozaki, Fukuoka, 812-8581, Japan
}

The swallowtail butterfly, Papilio xuthus, selectively uses a limited number of plants in the Rutaceae family. The butterfly detects oviposition stimulants in leaves through foreleg chemosensilla and requires a specific combination of multiple oviposition stimulants to lay eggs on the leaf of its host plants. In this study, we sought to elucidate the mechanism underlying the regulation of oviposition behavior by multiple oviposition stimulants. We classified chemosensilla on the tarsomere of the foreleg into three types (L1, L2, and S) according to their size and response to oviposition stimulants and general tastants. The L1 was more abundant in females than in males and responded preferentially to oviposition stimulants. Both L2 and S were common to both sexes and responded to general tastants. We found that five oviposition stimulants (synephrine, stachydrine, 5-hydroxy- $N \omega$-methyltryptamine, narirutin, and chiro-inositol) elicited spikes from three specific gustatory receptor neurons (GRNs) within L1 sensilla. These three GRNs responded to a mixture of the five stimulants at concentrations equivalent to those found in the whole-leaf extract of citrus, and the mixture induced oviposition at levels comparable to whole-leaf extract. We propose that oviposition is triggered by the firing of three specific GRNs in L1 sensilla that encode the chemical signatures of multiple oviposition stimulants.

\section{Introduction}

Host plant selection is a crucial behavior for mono- and oligophagous insects, because it conditions the success of individuals, particularly during larval development and reproduction. In Lepidoptera, choosing the right host plant during oviposition is particularly important, because the small larvae cannot easily forage for alternate host plants. Host plant selection by butterflies depends on several factors, including leaf color, shape, and phytochemical compounds (Rausher, 1978; Honda, 1995; Kelber, 1999). Among these, the phytochemical compounds are the most important factors for oviposition (Feeny et al., 1983). Females

\footnotetext{
Received March 21, 2012; revised Nov. 13, 2012; accepted Nov. 16, 2012

Author contributions: M.R., F.M.-P., T.T., and K.O. designed research; M.R., D.C.-L., and A.Y. performed research; M.R. and D.C.-L. analyzed data; M.R. and H.Y. wrote the paper.

This work was supported by a joint JSPS-INRA grant under the Japan-France Research Cooperative Program (T.T. and F.M.-P.) and by a grant from the Ministry of Education, (ulture, Sports, and Technology of Japan to T.T. We thank the members of Tanimura's laboratory at Kyushu University, especially Y. Seki and N. Shinzato, for the use of their electrophysiological setups and $\mathrm{H}$. Ishimoto for his kind help on scanning electron micrographs. We also thank members of the JT Biohistory Research Hall for useful discussions. We express our appreciation to M. Ozaki, H. Ono, and especially R. Nishida for useful discussions.

The authors declare no competing financial interests.

Correspondence should be addressed to Masasuke Ryuda, JT Biohistory Research Hall, Takatsuki, 0saka, 5691125, Japan. E-mail: masasuke.ryuda@brh.co.jp (mryuda5150@gmail.com).

D. Calas-List's present address: Laboratoire Récepteurs et Canaux Ioniques Membranaires, Université d'Angers, Angers, France.

DOI:10.1523/JNEUROSCI.1405-12.2013

Copyright $\odot 2013$ the authors $\quad 0270-6474 / 13 / 330914-11 \$ 15.00 / 0$
}

determine whether a plant is suitable for larval feeding by drumming on the leaf surface and perceiving chemicals through chemosensilla located on the ventral side of their foreleg tarsomeres (Ichinose and Honda, 1978).

Butterflies of the family Papilionidae lay eggs on the leaves of plants in the families Rutaceae, Apiaceae, or Lauraceae (Feeny et al., 1988; Honda, 1990; Carter et al., 1999). Phytochemical compounds acting as oviposition stimulants for the members of the Papilionidae have been identified in plants of the Rutaceae (Honda, 1990; Ohsugi et al., 1991; Ono et al., 2000a, b; Nakayama et al., 2003). Oviposition stimulants are classified as taste stimuli because they are nonvolatile compounds. Interestingly, each butterfly species requires a specific combination of chemicals in their host plants to lay eggs: Papilio xuthus requires a mixture of 10 chemicals, Papilio polytes 5, and Papilio protenor 6; each combination is found in their respective host plants (Honda, 1990; Ohsugi et al., 1991; Murakami, 2003). Notably, each of these chemicals fails to stimulate oviposition when they are used singly in oviposition behavioral assay (Honda, 1990; Ohsugi et al., 1991). Therefore, it is important to elucidate how multiple oviposition stimulants regulate oviposition behavior to understand the mechanism of host plant selection in Papilionidae.

We recently identified the gene PxutGr1, which encodes a gustatory receptor specific for synephrine, one of the 10 oviposition stimulants for P. xuthus (Ozaki et al., 2011). Given the specificity of this receptor, we hypothesized that the other nine 

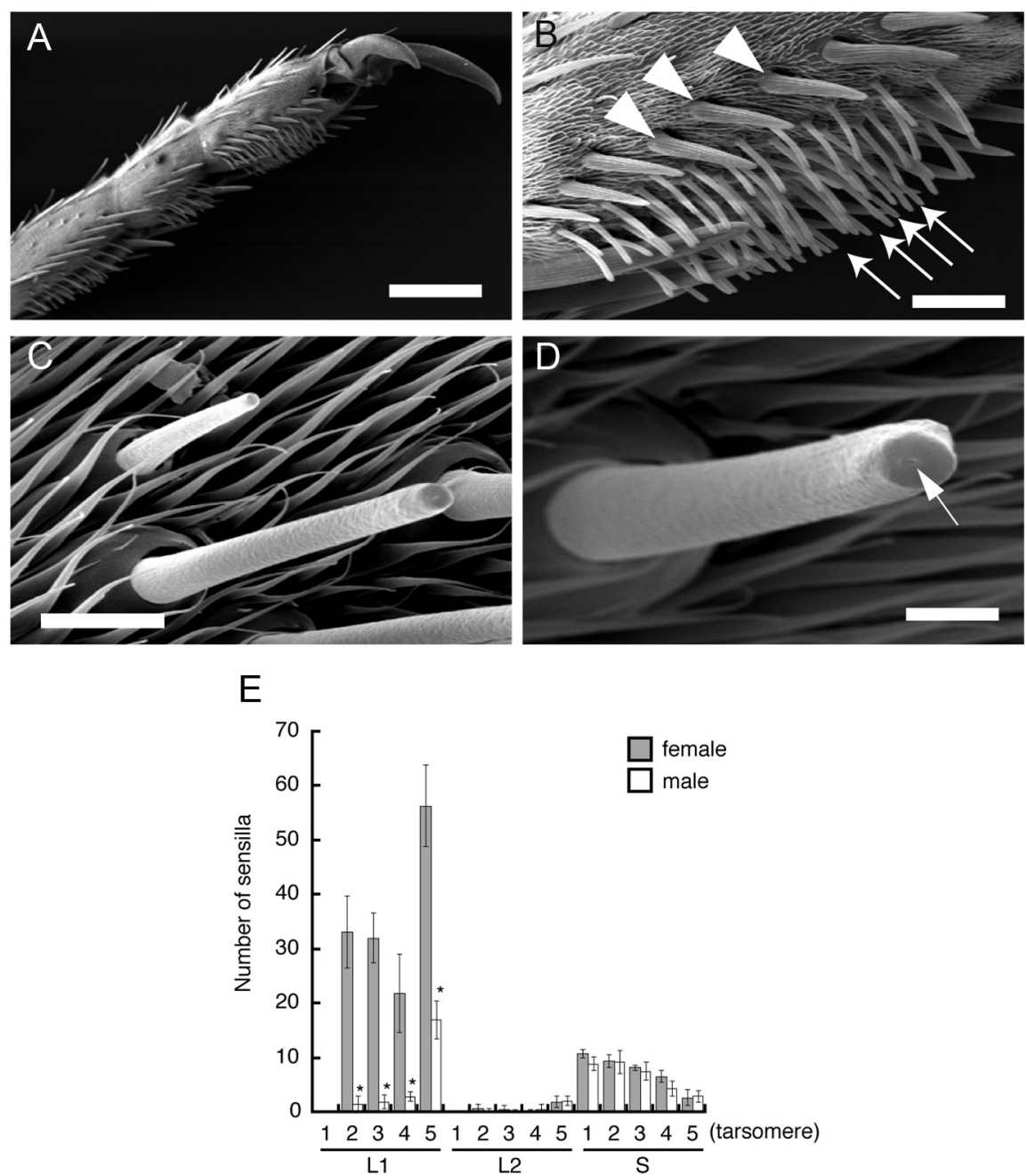

Figure 1. Scanning electron micrographs of foreleg tarsus and chemosensilla of the fifth tarsomere of $P$. xuthus. $A$, Ventral side of a female's foreleg tarsus. Scale bar, $300 \mu \mathrm{m}$. $\boldsymbol{B}$, Ventral side of a female's fifth tarsomere. Arrows and arrowheads indicate $L$ sensilla and bristles, respectively. Scale bar, $100 \mu \mathrm{m}$. C, Morphological differences between the L and S sensilla. Scale bar, $40 \mu \mathrm{m}$. $\boldsymbol{D}$, L sensillum on fifth tarsomere with single pore at the apex (arrow). Scale bar, $20 \mu \mathrm{m}$. $\boldsymbol{E}$, Numbers of sensilla on first to fifth tarsomeres (mean $\pm S D, n=6$ for first-fourth tarsomere, $n=21-42$ for fifth tarsomere). ${ }^{*} p<0.0001$ female versus male (Student's $t$ test). The second to fifth tarsomeres housed all three types of sensilla, whereas the first tarsomere had $S$ type sensilla only. Sexual dimorphism was observed only in the number of $L 1$ sensilla on the second to fifth tarsomeres. To count the number of L2 sensilla, $1 \mathrm{~mm} \mathrm{KCl}$ was applied to all $\mathrm{L}$ sensilla. The L sensilla that responded to sugars were $\mathrm{L} 2$ sensilla.

chemicals are also detected by specific chemoreceptors, each expressed in specialized taste cells. To test this hypothesis, we performed an extensive electrophysiological analysis of the responses of these taste cells. Because the cellular composition of sensilla in the foreleg tarsus has not been precisely described, we first classified the sensilla by shape and location into several types and recorded their responses to oviposition stimulants as well as to commonly used taste compounds. We also examined the correlation between the response pattern of the taste cells and the oviposition behavior. Our findings indicated that the detection of these oviposition-specific chemicals occurs through a specific neural pathway in Papilionidae.

\section{Materials and Methods}

Animals. Adult females of P. xuthus were collected at Takatsuki, Osaka, Japan, and allowed to lay eggs on young leaves of Citrus unshiu in the laboratory. Larvae were reared on an artificial diet containing Insecta F-II (Nihon Nosan) and dry Zanthoxylum ailanthoides (collected at Takat- suki, Osaka, Japan) leaves reduced to a powder, at $25 \pm 3^{\circ} \mathrm{C}$ under $16 / 8 \mathrm{~h}$ light $/$ dark conditions.

Chemicals. D,L-Synephrine was purchased from MP Biochemicals. 1(-)-Stachydrine and narirutin were obtained from Extrasynthese. 5-Hydroxy- $N \omega$-methyltryptamine, chiro-inositol, rutin, hesperidin, adenosine, $\mathrm{KCl}, \mathrm{NaCl}$, sucrose, glucose, fructose, dimethyl sulfoxide, and 2-hydroxypropyl- $\beta$-cyclodextrin were purchased from Wako Pure Chemical Industries. Caffeine was obtained from SigmaAldrich. Quinine hydrochloride was purchased from Tokyo Kasei Chemicals. For electrophysiological recordings, all compounds were dissolved in $1 \mathrm{~mm} \mathrm{KCl}$ prepared using distilled water and stored at $-20^{\circ} \mathrm{C}$, and $1 \mathrm{mM} \mathrm{KCl}$ was used in all experiments as the electrolyte. In Drosophila melanogaster and Phormia regina, 1 $\mathrm{mm} \mathrm{KCl} \mathrm{elicits} \mathrm{spikes} \mathrm{from} \mathrm{the} \mathrm{water} \mathrm{cell} \mathrm{but}$ not from other cells (Evans and Mellon, 1962; Hiroi et al., 2002).

Preparation of whole-leaf citrus extract. The whole-leaf citrus extract was prepared as described by Honda (1986). Briefly, young leaves of Citrus unshiu were extracted with 100\% methanol at $25 \pm 3^{\circ} \mathrm{C}$ for 1 month. The methanol extract was concentrated in vacuo at $50^{\circ} \mathrm{C}$, and an aliquot was dissolved in an amount of water equivalent to the wet weight of the leaves. This extract was designated $1.0 \times$ citrus extract.

Electrophysiological recordings. We used $0-8$-d-old adults for the electrophysiological recordings. There are essentially no differences in nature of responses to various stimulants among sensilla prepared from adults of varying in age (data not shown). A foreleg (tarsus, tibia, and femur) was removed from the body using forceps and then fixed on a polystyrene block with fine strips of sticky paper tape. A glass capillary electrode filled with Ringer's solution $\left(\mathrm{CaCl}_{2} \mathrm{H}_{2} \mathrm{O} ; 3 \mathrm{~mm}, \mathrm{KCl} ; 182 \mathrm{~mm}, \mathrm{NaCl} ; 46\right.$ $\mathrm{mm}$, Tris base; $10 \mathrm{~mm}, \mathrm{pH}$ 7.2) was inserted into the leg and connected to the ground. The leg was oriented such that sensilla from the ventral side of the fifth tarsomere were accessible to stimulation by glass capillary electrodes (diameter $\sim 20 \mu \mathrm{m}$ ) filled with a solution of a given compound. Nerve responses were recorded using the tip-recording method (Hodgson et al., 1955; Calas et al., 2006). The electrical signal was amplified by a TastePROBE preamplifier DTP-02 (Syntech) (Marion-Poll and van der Pers, 1996) and further amplified and filtered $(10-2800 \mathrm{~Hz})$ by a CyberAmp 320 amplifier (Molecular Devices). Data were recorded and stored on a computer with a 16-bit A/D conversion card DT9803 USB A/D (Data Translation) under the control of the custom software dbWave (Marion-Poll, 1995, 1996).

Recordings were analyzed using dbWave (http://taste.versailles.inra. fr/deterrents/tk/dbwave/) to detect and sort spikes according to their amplitude and shape. We paid particular attention to correlate our recordings to L1, L2, and S sensilla types. Within the L1 sensilla, we counted the number of responsive and nonresponsive sensilla for a given stimulus. For the "responsive" sensilla, we evaluated the number of active cells based on the spike shape and the presence of doublet spikes, which indicate that at least 2 cells are active (Meunier et al., 2003). All electrophysiological data for L2 and S sensilla were combined, because these sensilla showed almost identical electrophysiological responses to all tested compounds (data not shown).

Assay for oviposition behavior. Females were hand-paired on the day of (or $1 \mathrm{~d}$ after) eclosion. For the assay, we used mated 3-6 d-old females, 

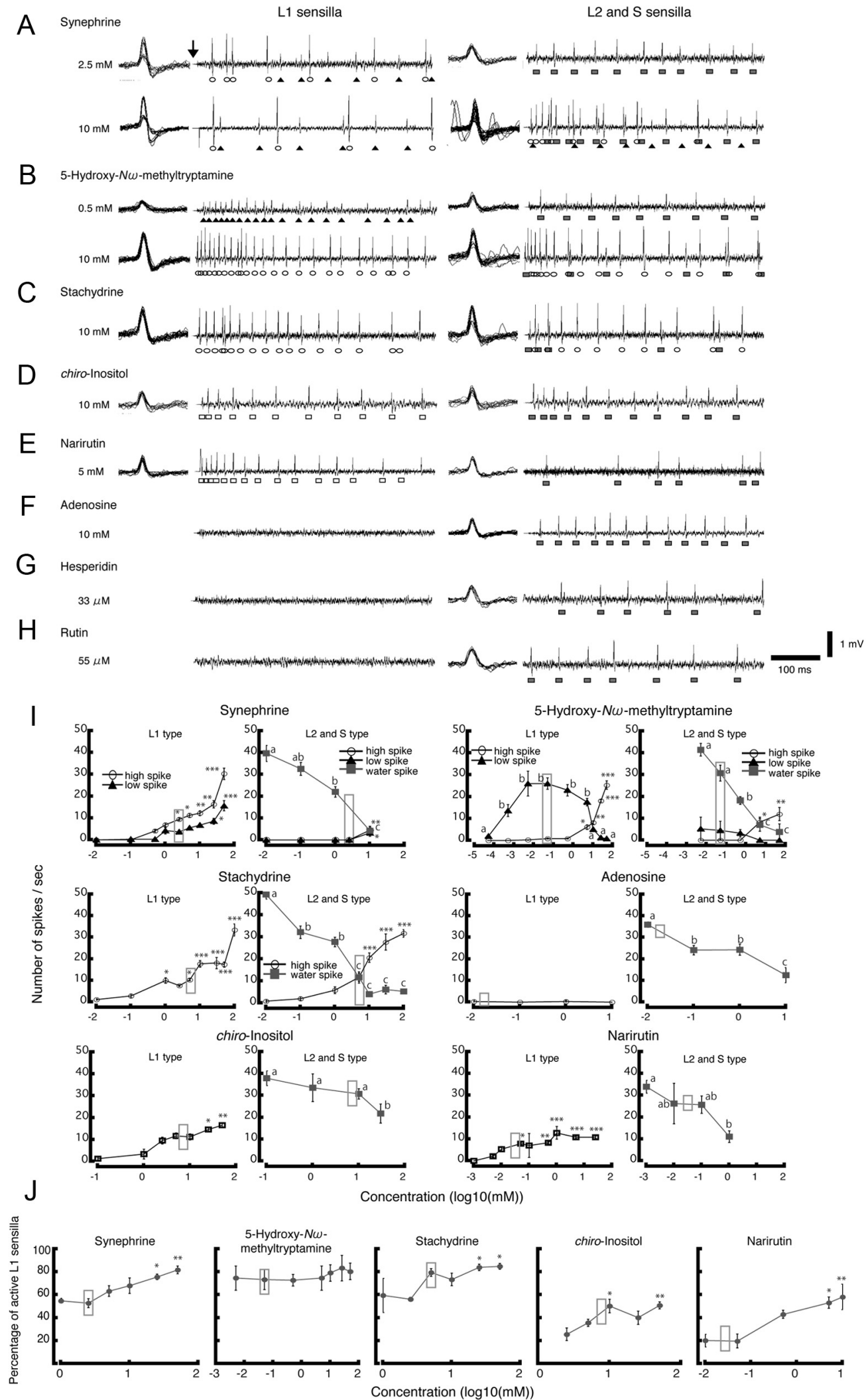

Figure 2. Typical electrophysiological recordings of L1 sensilla (left column) and L2 or S sensilla (right column) on the fifth tarsomere in response to eight oviposition stimulants during the first $500 \mathrm{~ms}$ after stimulation. Vertical bar indicates $1.0 \mathrm{mV}$. Arrow indicates the onset of stimulation. To the left of each trace, the spikes are superimposed. Open circles, open squares, and triangles indicate the positions of high $(1.0-1.5 \mathrm{mV})$, intermediate $(0.6-0.8 \mathrm{mV})$, and low $(0.2-0.4 \mathrm{mV})$ spikes, respectively. Gray squares indicate spikes elicited by water $(0.6-0.8 \mathrm{mV})$. Recordings show responses to $\boldsymbol{A}, 2.5$ and $10 \mathrm{~mm}$ synephrine; $\boldsymbol{B}, 0.5$ and $10 \mathrm{~mm}$ 5-hydroxy- $N \omega$-methyltryptamine; $\boldsymbol{C}, 10 \mathrm{~mm}$ stachydrine; $\boldsymbol{D}, 10 \mathrm{~mm}$ chiro-inositol; $\boldsymbol{E}, 5 \mathrm{~mm}$ narirutin; $\boldsymbol{F}, 10 \mathrm{~mm}$ adenosine; $\boldsymbol{G}, 33 \mu \mathrm{m}$ hesperidin; and $\boldsymbol{H}, 55 \mu \mathrm{m}$ rutin. $\boldsymbol{I}$, Electrophysiological responses of L1 (left column) and L2 or S sensilla (right column) to increasing concentrations of six oviposition stimulants in females (mean \pm SE spike frequencies; $n=7-88$ for synephrine, $n=5-70$ for 5 -hydroxy-N $\omega$-methyltryptamine, $n=7-80$ for stachydrine, $n=6-19$ for adenosine, $n=6-53$ for chiro-inositol, and $n=5-54$ for narirutin). Gray boxes indicate the estimated concentrations of oviposition stimulants in intact leaves of C. unshiu, as described previously (Nishida et al., 1987; (Figure legend continues.) 
because $0-2 \mathrm{~d}$-old females displayed low $(20-50 \%)$ oviposition activity with citrus extracts, and some females older than $7 \mathrm{~d}$ laid eggs even on artificial green leaves immersed in water alone. One hour before starting the assay, we extended the proboscis of all females with a toothpick and fed them $100 \mathrm{~mm}$ sucrose solution in cotton. After feeding, they were placed in a rearing container illuminated by a $12-\mathrm{W}$ fluorescent light. A female was introduced into an assay box $(30 \times 25 \times 25 \mathrm{~cm}$ high $)$, illuminated by a $12-\mathrm{W}$ fluorescent light just before the experiment. Artificial plastic green leaves were briefly immersed in plain water or in a solution of the citrus extract, mixtures of oviposition stimulants, or single stimulants just before they were presented to the female. We presented the wetted artificial leaf to each female for $2 \mathrm{~min}$ and then examined it for eggs to assess the oviposition responses to each solution.

Scanning-electron microscopy. Tarsi of female butterflies were removed from body by using forceps, dehydrated in an acetone series, dried in air. Mounted legs were sputter-coated with gold and observed by a JSM-5300 LV scanning electron microscope (JEOL).

Statistical analysis. Paired comparison and group comparison were made with the Student's $t$ test and the one-way ANOVA followed by Tukey-Kramer post hoc test, respectively, using KaleidaGraph Version 4.01 (Synergy Software). A correlation coefficient between the number of spikes and oviposition activities was calculated by Microsoft Excel for Mac, 2011 Version 14.2.4 (Microsoft).

\section{Results}

\section{Three types of sensilla are present in the foreleg tarsomeres}

We classified sensilla in the first to fifth tarsomere of the $P$. xuthus foreleg on the basis of their position and morphology using scanning electron microscopy (SEM) observations (Fig. 1A-D). Sensilla could be classified by length into two types, short $(S, \sim 50$ $\mu \mathrm{m}$ ) and long (L, $\sim 100 \mu \mathrm{m})$ (Fig. $1 C$ ). The $\mathrm{L}$ sensilla were further classified into types 1 (L1) and 2 (L2) (Fig. 1E) according to their electrophysiological responses (see Figs. 2, 4). No sex-related differences were noted in the numbers of L2 and S sensilla, but females had more L1 sensilla than males (Student's $t$ test; $t_{(10)}=$ $11.379, p<0.0001$ for second tarsomere; $t_{(10)}=15.419, p<$ 0.0001 for third tarsomere, $t_{(10)}=6.4789, p<0.0001$ for fourth tarsomere, and $t_{(40)}=32.92, p<0.0001$ for fifth tarsomere). Because L1 sensilla are most abundant in the fifth tarsomere (Tukey-Kramer test; $F_{(3,35)}=52.82, p<0.0001$ for female, and $F_{(3,35)}=95.29, p<0.0001$ for male), further electrophysiological analyses were performed with the sensilla in the female fifth tarsomere. Electrophysiological responses by each type of sensilla on other tarsomere are the same as those in the fifth tarsomere (data not shown).

\section{Electrophysiological response of fifth tarsomere chemosensilla to oviposition stimulants}

We analyzed the electrophysiological responses to 8 of the 10 identified oviposition stimulants of P. xuthus (Fig. 2). Two

$\leftarrow$

(Figure legend continued.) Ohsugi et al., 1991). These concentrations were as follows: synephrine: $2.4 \mathrm{~mm}$; 5-hydroxy- $\mathrm{N} \omega$-methyltryptamine: $0.04 \mathrm{~mm}$; stachydrine: $5.1 \mathrm{~mm}$; adenosine: $0.02 \mathrm{~mm}$; chiro-inositol: $8.3 \mathrm{~mm}$; and narirutin: $0.03 \mathrm{~mm}$. The number of spikes was calculated during the first second. Different letters $(a-c)$ indicate significant differences of water spikes in $\mathrm{L} 2$ and $\mathrm{S}$ sensilla and low spikes of 5 -hydroxy- $N \omega$-methyltryptamine in L1 sensilla among concentrations by the Tukey-Kramer test $(p<0.05) .{ }^{*} p<0.05,{ }^{* *} p<0.01$, ${ }^{* * *} p<0.0001$ versus $0.01 \mathrm{~mm}$ synephrine, $0.00005 \mathrm{~mm} 5$-hydroxy- $N \omega$-methyltryptamine, $0.01 \mathrm{~mm}$ stachydrine, $0.01 \mathrm{~mm}$ adenosine, $0.1 \mathrm{~mm}$ chiro-inositol, and $0.001 \mathrm{~mm}$ narirutin, respectively. J, Percentage of $\mathrm{L} 1$ sensilla responding to increasing concentrations of five oviposition stimulants (mean \pm SE the percentage of responding sensilla; $n=7-14$ for synephrine, $n=3-6$ for 5-hydroxy- $N \omega$-methyltryptamine, $n=4-18$ for stachydrine, $n=5-7$ for chiro-inositol, and $n=4$ or 5 for narirutin). Each value of independent recording was the average response of $10-20$ sensilla per individual. ${ }^{*} p<0.05 ;{ }^{* *} p<0.01$, versus 1 mm synephrine, $0.005 \mathrm{~mm}$ 5-hydroxy- $N \omega$-methyltryptamine, $1 \mathrm{~mm}$ stachydrine, $2.5 \mathrm{~mm}$ chiro-inositol, and $0.01 \mathrm{~mm}$ narirutin, respectively. chemicals, vicenin-2 and bufotenine, were not tested because they were not commercially available. The L1 sensilla responded to five stimuli: synephrine, stachydrine, 5-hydroxy$N \omega$-methyltryptamine, chiro-inositol, and narirutin (Fig. $2 A-E$ ). Synephrine and 5-hydroxy- $N \omega$-methyltryptamine each elicited 2 types of spikes, high amplitude $(1.0-1.5 \mathrm{mV})$ and low amplitude $(0.2-0.4 \mathrm{mV}$ ) (Fig. 2A,B). The $\mathrm{L} 1$ sensilla responded to synephrine in one of three ways: high-amplitude spikes alone, low-amplitude spikes alone, or a combination of the two. The dose-response curves of L1 sensilla to synephrine show that the gustatory receptor neurons (GRNs) with high-amplitude spikes were more sensitive to synephrine than the GRNs with low-amplitude spikes (Fig. 2I; Student's $t$ test; $t_{(16)}=6.7002, p<0.0001$ for $0.5 \mathrm{~mm}$, $t_{(78)}=5.7475, p<0.0001$ for $2.5 \mathrm{mM}, t_{(64)}=4.8299, p<0.0001$ for $5.0 \mathrm{mM}, t_{(173)}=3.8567, p=0.0001619$ for $10 \mathrm{mM}, t_{(76)}=$ 3.6836, $p=0.0004283$ for $25 \mathrm{~mm}$, and $t_{(46)}=4.2388, p=$ 0.000107 for $50 \mathrm{~mm}$ ). The response of L1 sensilla to 5-hydroxy$\mathrm{N} \omega$-methyltryptamine switched from high- to low-amplitude spikes between 5 and $10 \mathrm{~mm}$ (Fig. 2I), indicating that the two GRNs of in L1 sensillum responded separately to different concentrations of 5-hydroxy-N $\omega$-methyltryptamine. Stimulation with stachydrine, chiro-inositol, and narirutin each elicited only a single type of spike: stachydrine: $1.0-1.5 \mathrm{mV}$, chiro-inositol and narirutin: $0.6-0.8 \mathrm{mV}$ (Fig. $2 C-E$ ). The numbers of spikes elicited by stachydrine, chiro-inositol, and narirutin increased with concentration (Fig. $2 I ; F_{(8,422)}=21.55, p<0.0001$ for stachydrine, $F_{(7,264)}=7.29, p<0.0001$ for chiro-inositol, and $F_{(8,217)}=$ 17.93, $p<0.0001$ for narirutin). Adenosine, hesperidin, and rutin did not elicit any spikes in L1 sensilla (Fig. $2 F-H$ ). Because hesperidin and rutin dissolve poorly in water and ethanol, we used $10 \%$ dimethyl sulfoxide or $20 \%$ 2-hydroxypropyl- $\beta$ cyclodextrin as a solvent (Calabrò et al., 2005; Majumdar and Srirangam, 2009). No response was found to $1 \mathrm{~mm}$ hesperidin or rutin (data not shown). Because estimated concentrations of hesperidin and rutin in intact leaves of Citrus unshiu are 0.66 and $0.25 \mathrm{~mm}$, respectively (Nishida et al., 1987), these concentrations may not be sufficient to be detected by L1 sensilla.

In contrast to L1 sensilla, L2 and S sensilla exhibited spikes (0.6$0.8 \mathrm{mV}$ ) in response to 8 oviposition stimulants (Fig. $2 A-H$ ). These spikes decreased in frequency with increasing stimulant concentration, except for hesperidin and rutin (Fig. 2I; synephrine; $F_{(3,55)}=26.07, p<0.0001,5$-hydroxy- $N \omega$-methyltryptamine; $F_{(4,25)}=24.57, p<0.0001$, stachydrine; $F_{(6,115)}=32.57, p<0.0001$, adenosine; $F_{(3,43)}=14.03, p<0.0001$, chiro-inositol; $F_{(3,27)}=3.451$, $p=0.03036$, and narirutin; $\left.F_{(3,22)}=5.169, p=0.00513\right)$. These results indicated that these spikes originated from a "water" cell, because water cells function as osmometer and their responses are usually inhibited by increasing concentrations of a given compound (Evans and Mellon, 1962). The L2 and S sensilla were less sensitive to synephrine and 5-hydroxy-N $\omega$-methyltryptamine than L1 sensilla at whole-leaf concentrations (Fig. 2I; Student's $t$ test; $t_{(56)}=7.5563$, $p<0.0001$ for high spikes of synephrine, $t_{(42)}=2.5281, p=$ 0.01532 for low spikes of synephrine, and $t_{(76)}=2.8164, p=$ 0.006184 for low spike of 5-hydroxy- $N \omega$-methyltryptamine), but responded to stachydrine comparably to L1 sensilla (Fig. 2I; Student's $t$ test; $t_{(87)}=0.94073, p=0.3494$ for stachydrine). chiro-Inositol, narirutin, and adenosine elicited water spikes only, indicating that these compounds were not recognized. Spikes elicited by hesperidin and rutin were indistinguishable from water spikes (Fig. $2 G, H$ ), because we could not confirm the dose dependency of responses to these stimulants.

We also examined the percentage of L1 sensilla on the fifth tarsomere responding to a given stimulus (Fig. $2 J$ ). The percentages of 
A

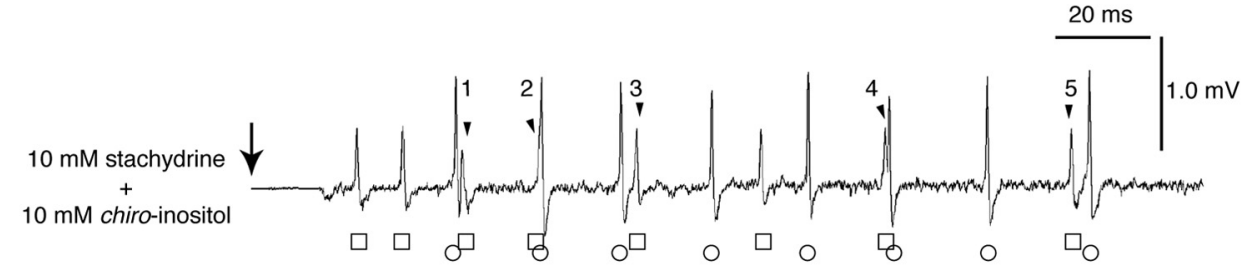

B
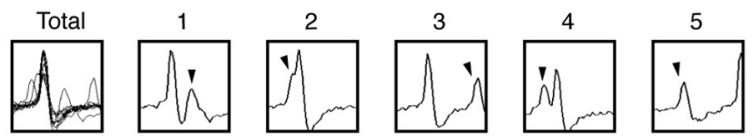

$\pi^{1.0 \mathrm{~ms}}$

O os1 spike

$\Delta$ os3 spike

\begin{tabular}{|c|c|}
\hline & $\begin{array}{c}10 \mathrm{mM} \text { chiro-inositol } \\
+ \\
2.5 \mathrm{mM} \text { synephrine } \\
(2 \mathrm{GRNs})\end{array}$ \\
\hline J & $\begin{array}{c}10 \mathrm{mM} \text { chiro-inositol } \\
+ \\
10 \mathrm{mM} \text { synephrine } \\
\text { (3 GRNs) }\end{array}$ \\
\hline$E$ & $\begin{array}{c}10 \mathrm{mM} \text { synephrine } \\
+ \\
5 \mathrm{mM} \text { narirutin } \\
(3 \mathrm{GRNs})\end{array}$ \\
\hline$F$ & $\begin{array}{c}10 \mathrm{mM} \text { stachydrine } \\
+ \\
1 \mathrm{mM} \text { 5-hydroxy-N } \omega \text {-methyltryptamine } \\
(2 \mathrm{GRNs})\end{array}$ \\
\hline & $\begin{array}{c}10 \mathrm{mM} \text { stachydrine } \\
+ \\
2.5 \mathrm{mM} \text { synephrine } \\
\text { (2 GRNs) }\end{array}$ \\
\hline 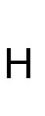 & $\begin{array}{c}10 \mathrm{mM} \text { stachydrine } \\
++ \\
10 \mathrm{mM} \text { 5-hydroxy- } \mathrm{N} \omega \text {-methyltryptamine } \\
(1 \mathrm{GRN})\end{array}$ \\
\hline 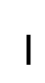 & $\begin{array}{c}10 \mathrm{mM} \text { chiro-inositol } \\
+ \\
5 \mathrm{mM} \text { narirutin }\end{array}$ \\
\hline
\end{tabular}

(1 GRN)

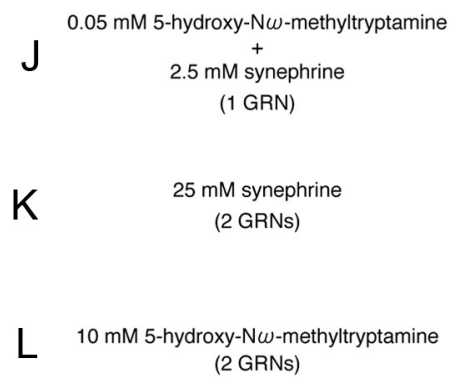

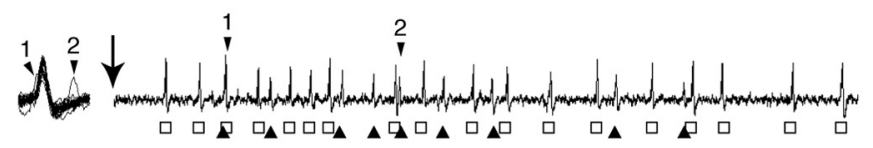
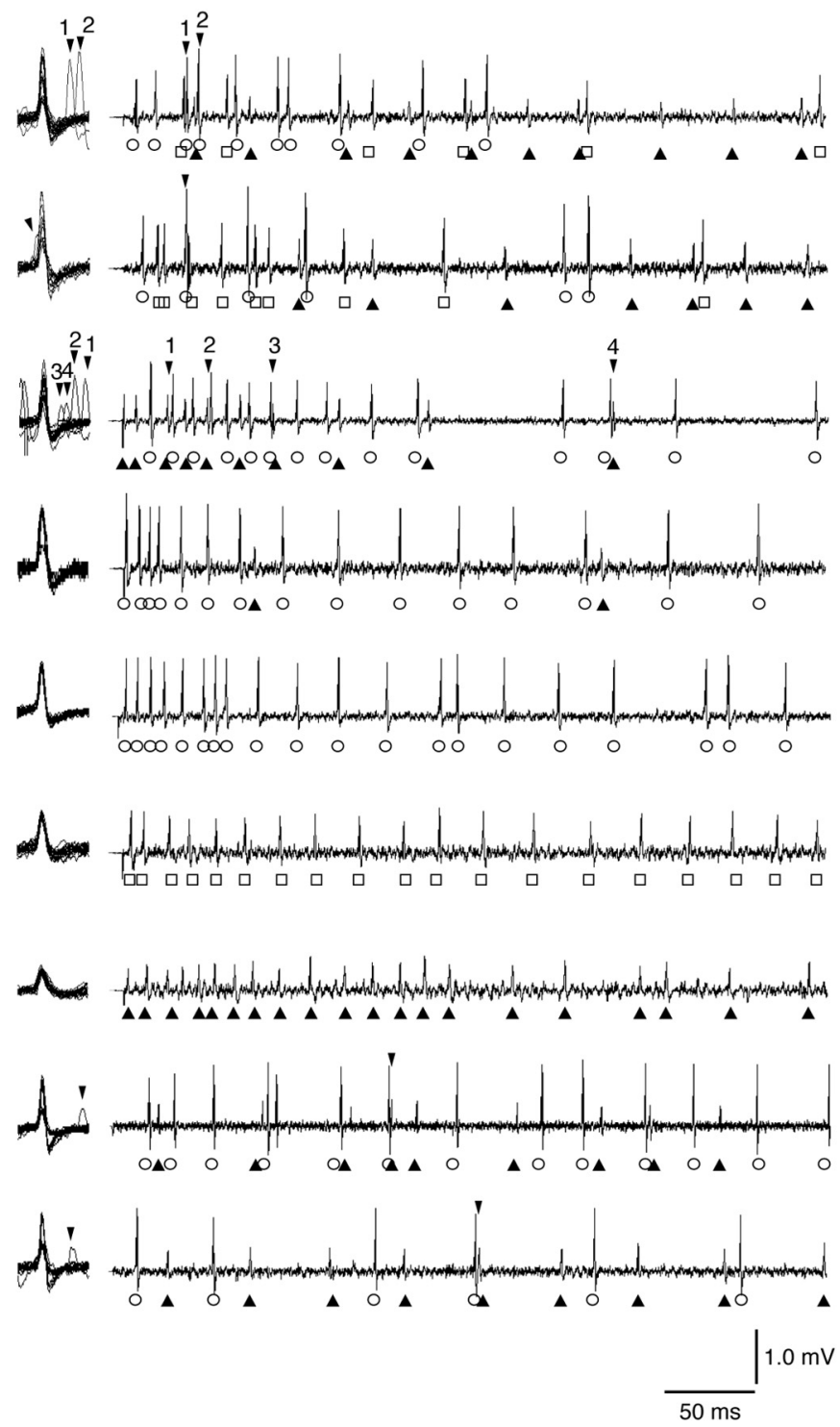

Figure 3. Responses of $L 1$ sensilla on the fifth tarsomere to mixtures of two oviposition stimulants. $A$, Sample responses of $L 1$ sensilla to $10 \mathrm{~mm}$ stachydrine plus $10 \mathrm{~mm}$ chiro-inositol. 0 viposition spike 1 (os1, circles) and os2 (squares) spikes are shown. Arrowheads indicate the doublet spikes. $\boldsymbol{B}$, Total spikes and doublets. Total spikes indicate superimposed spikes of trace A. Doublet spikes 1-5 are shown by arrowheads. C, Response to $2.5 \mathrm{~mm}$ synephrine and $10 \mathrm{~mm}$ chiro-inositol. Arrowheads indicate doublets of os 2 and os 3 (triangles). $\boldsymbol{D}$, Response to $10 \mathrm{~mm}$ synephrine and $10 \mathrm{~mm}$ chiro-inositol. The mixture elicited three types of spikes simultaneously. Arrowheads 1 and 2 indicate doublets consisting of os $1+$ os 2 and os $1+$ os 3 , respectively. $\boldsymbol{E}$, Response to $10 \mathrm{~mm}$ synephrine and $5 \mathrm{~mm}$ narirutin. The mixture elicited three types of spikes. Arrowhead indicates a doublet of os 1 and os 2 . $F$, Response to $10 \mathrm{~mm}$ stachydrine and $1.0 \mathrm{~mm}$ (Figure legend continues.) 
responding sensilla increased with the stimulant concentrations, except for 5-hydroxy- $N \omega$-methyltryptamine (synephrine; $F_{(5,55)}=$ $6.311, p=0.00011$, stachydrine; $F_{(5,53)}=6.995, p<0.0001$, chiroinositol; $F_{(4,22)}=5.227, p=0.00409$, and narirutin; $F_{(4,17)}=7.769$, $p=0.00094$ ). These five stimulants exhibited various success rates of recordings in response to the close concentrations of these compounds found in whole-leaf extracts (the percentage of responding sensilla of $2.5 \mathrm{~mm}$ synephrine, $5 \mathrm{~mm}$ stachydrine, 0.05 mM 5-hydroxy- $N \omega$-methyltryptamine, $10 \mathrm{~mm}$ chiro-inositol, and $0.05 \mathrm{~mm}$ narirutin; $\left.F_{(4,26)}=19.39, p<0.0001\right)$. These results suggested that L1 sensilla house different numbers of GRNs for each oviposition stimulant.

\section{Three GRNs respond to five oviposition stimulants}

To determine whether spikes elicited by five stimulants arise from discrete or identical GRNs in L1 sensilla on the fifth tarsomere, we examined doublet spikes elicited by mixtures of two oviposition stimulants, synephrine, and 5-hydroxy- $N \omega$-methyltryptamine (Fig. 3). The doublet spikes are known to occur when more than one GRN are activated (Meunier et al., 2003; Hiroi et al., 2004). The mixture of stachydrine and chiro-inositol elicited two types of spikes: high $(1.0-1.5 \mathrm{mV})$ and low amplitude $(0.6-0.8 \mathrm{mV})$ (Fig. $3 A$ ). Each type contained doublet spikes of the same amplitude and shape as individual spikes elicited by each single stimulant (Fig. $3 A, B$ ), indicating that the two stimulants are perceived by discrete GRNs. Likewise, doublet spikes were elicited by mixtures of two stimulants that elicited spikes with different amplitude when used individually (Fig. $3 C-F$ ). In contrast, when mixtures of stimulants that elicited spikes of the same amplitude were used, no doublet spikes were observed (Fig. $3 G-J$ ). These results suggested that spikes of the same amplitude are elicited by the same GRN, regardless of stimulants. Synephrine and 5-hydroxy- $N \omega$-methyltryptamine each elicited doublet spikes, even when they were used individually (Fig. $3 K, L$ ), indicating that two different GRNs responded to these stimulants. These results suggested that L1 sensilla house three GRNs that can respond to five oviposition stimulants. Therefore, we defined the high-amplitude spike elicited by synephrine, stachydrine, and 5-hydroxy- $N \omega$-methyltryptamine as oviposition spike 1 (os1), the intermediate-amplitude spike (by chiro-inositol and narirutin) as os2, and the low-amplitude spike (by synephrine and 5-hydroxy- $N \omega$-methyltryptamine) as os3.

\section{Electrophysiological responses to sugar, salt, and bitter compounds}

The L1 sensilla appear to be specialized in their responses to oviposition stimulants and differ from L2 and S sensilla. To further examine the differences among sensilla, we studied their responses to sugar, salt, and bitter compounds. Responses to sugar were observed only in L2 and S sensilla (Fig. $4 A-C, J$ ). Responses to salt varied with salt concentrations: highconcentration salts $(>100 \mathrm{~mm} \mathrm{KCl}$ and $\mathrm{NaCl}$ ) elicited spikes $(1.5-2.0 \mathrm{mV}$ ) in all types of sensilla (Fig. $4 E, G, J)$. In contrast, no

(Figure legend continued.) $\quad 5$-hydroxy-N $\omega$-methyltryptamine. The mixture elicited two types of spikes. Arrowheads indicate four doublets of os 1 and os3. G, Response to $10 \mathrm{~mm}$ stachydrine and $2.5 \mathrm{~mm}$ synephrine. $\boldsymbol{H}$, Response to $10 \mathrm{~mm}$ stachydrine and $10 \mathrm{~mm}$ 5-hydroxy- $\mathrm{N} \omega$ methyltryptamine. $I$, Response to $10 \mathrm{~mm}$ chiro-inositol and $5 \mathrm{~mm}$ narirutin. J, Response to 0.05 mм 5-hydroxy- $N \omega$-methyltryptamine and $2.5 \mathrm{~mm}$ synephrine. Mixtures $\mathbf{G}-\mathbf{J}$ each elicited a single type of spike. $\boldsymbol{K}$, Responses to $25 \mathrm{~mm}$ synephrine and $\boldsymbol{L}, 10 \mathrm{~mm}$ 5-hydroxy- $\mathrm{N} \omega$ methyltryptamine. Arrowheads indicate doublets of os 1 and os3. Arrows indicate the onset of stimulation. Trace $\boldsymbol{A}$ lasted $200 \mathrm{~ms}$ and traces $\boldsymbol{C}-\boldsymbol{L} 500 \mathrm{~ms}$. spikes were found in L1 sensilla when low-concentration salts were used (Fig. $4 D, F, J$ ). Bitter compounds (caffeine and quinine) elicited spikes in all types of sensilla (Fig. $4 \mathrm{H}-J$ ).

\section{Relationship between sensilla's response patterns and oviposition-inducting activity}

We next examined the correlation between electrophysiological responses and oviposition-inducing activity using whole-leaf citrus extract and mixtures of oviposition stimulants. First, we examined sensilla responses to the whole-leaf extract $(1.0 \times$ citrus extract), which showed full (100\%) oviposition-inducing activity in assays for oviposition behavior in two previous reports (Ohsugi et al., 1991; Ozaki et al., 2011). The 1.0× citrus extract elicited at least 3-4 types of spikes in L1 sensilla, but only one type in L2 and S sensilla (high-amplitude: $1.0-1.5 \mathrm{mV}$ ) (Fig. 5A). To examine the dose dependency of these responses by L1 sensilla, the citrus extract was used at four different dilutions from 0.001 to 1.0 (Fig. 5A). A dose-dependent increase in the frequency of all types of spikes was observed (Fig. $5 \mathrm{~A}$, Table 1; high spikes; $F_{(3,58)}=$ 23.95, $p<0.0001$, intermediate spikes; $F_{(3,58)}=9.643, p<0.0001$, and low spikes; $\left.F_{(3,58)}=26.91, p<0.0001\right)$. We then examined responses of L1 sensilla to several mixtures of oviposition stimulants that were predicted to elicit two or three types of spikes simultaneously, based on the spike patterns of individual stimulants (Fig. 5B). The data indeed showed that each mixture elicited the spike pattern expected from individual patterns.

We asked whether there are correlations between the spiking responses and the oviposition activity of mixtures (Fig. 5C). Mixtures of four or five stimulants $(1+2+3+4+5,1+2+3+4)$, which elicit three types of spikes (Fig. $5 B$ ), induced oviposition behaviors comparable to the citrus extract (Fig. 5C; oviposition activities of the citrus extract, $1+2+3+4+5$, and $1+2+3+4$; $\left.F_{(2,21)}=3.0727, p=0.06753\right)$, while a mixture of four stimulants $(2+3+4+5)$ showed lower activity $(77.4 \pm 4.0 \%)$ than the citrus extract (oviposition activities of the citrus extract and mixtures of four or five stimulants; $F_{(3,35)}=5.799, p=0.0025$ ). Mixtures of three oviposition stimulants showed different oviposition activity according to the number of spike types activated (Fig. 5B,C). Approximately $60 \%$ oviposition activity was induced by mixtures eliciting three types of spikes $(2+3+4,1+2+4,1+4+5)$, while mixtures eliciting two types of spikes $(2+4+5$ and $3+4+5)$ showed low induction activity (oviposition activities of five mixtures of three stimulants; $\left.F_{(4,50)}=25.87, p<0.0001\right)$. Mixtures of only two compounds showed contrasting results (Fig. $5 C$ ). The mixtures of synephrine and chiro-inositol $(1+4)$ and synephrine and narirutin $(1+5)$ that elicited three types of spikes (Fig. 3D,E) induced relatively high oviposition behavior $(47.6 \pm 3.0 \%$ and $39.4 \pm 3.5 \%$, respectively; oviposition activities of eight mixtures of two stimulants; $\left.F_{(7,44)}=13.37, p<0.0001\right)$, whereas other binary mixtures eliciting only one or two spike types (Fig. 3 and data not shown) barely induced any oviposition behavior. Neither water nor any single oviposition stimulant induced any oviposition (Fig. 5C). These results suggest that combinations of stimulants that elicit all three types of spikes, os1, os2, and os3, are necessary to induce the oviposition behavior.

Oviposition inducing activity by mixtures that elicited three types of spikes varied, suggesting that other factors, such as the frequency of elicited spikes, may affect their potency. A linear correlation was observed between the frequency of the total number of spikes and the oviposition activity elicited by $0.001-0.1 \times$ citrus extracts and mixtures of oviposition stimulants eliciting three types of spikes (Fig. 5D, Tables 2, 3; the correlation coefficient of $0.001-0.1 \times$ citrus extracts and mixtures of oviposition 
L1 sensilla

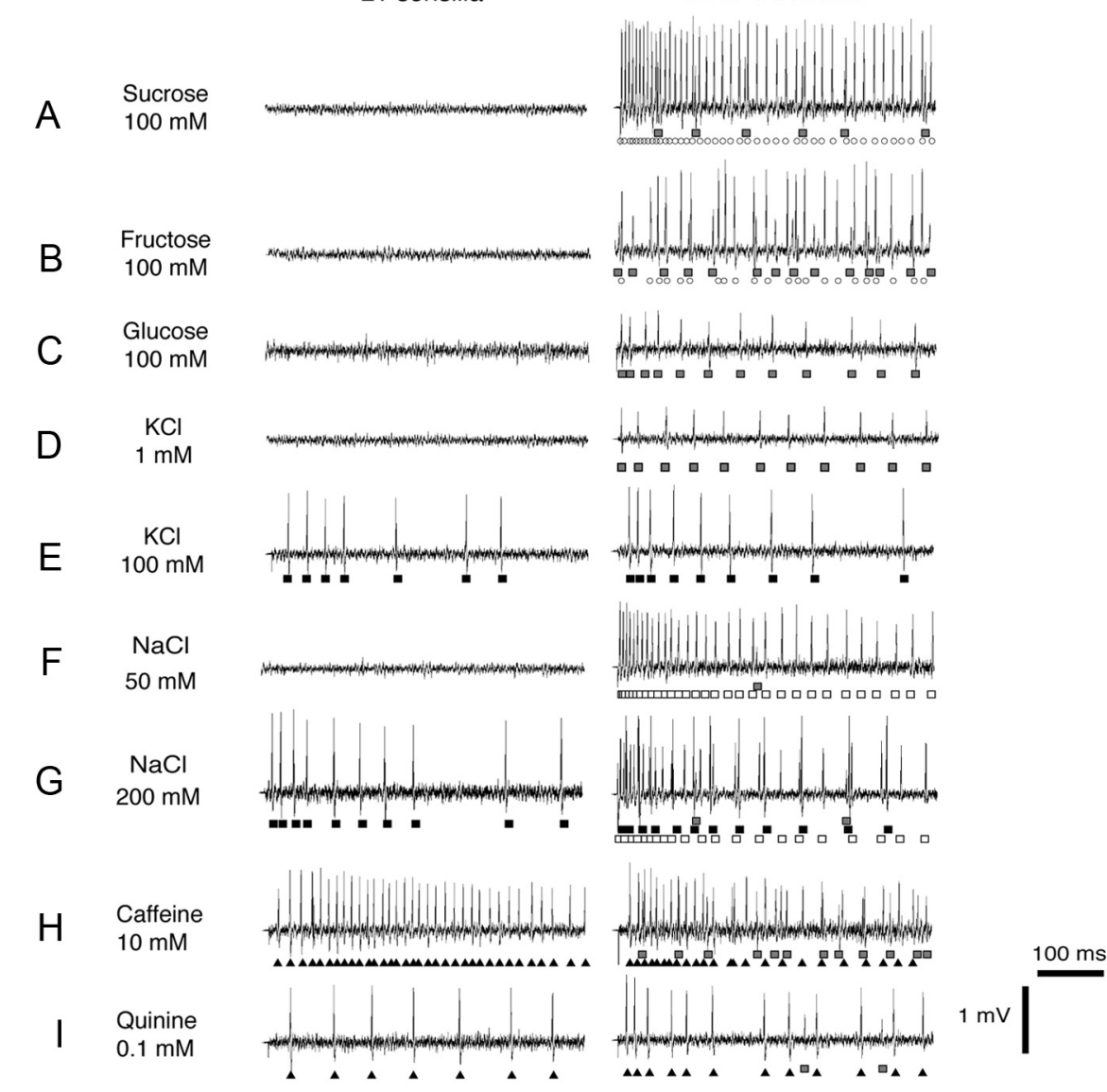

$J$
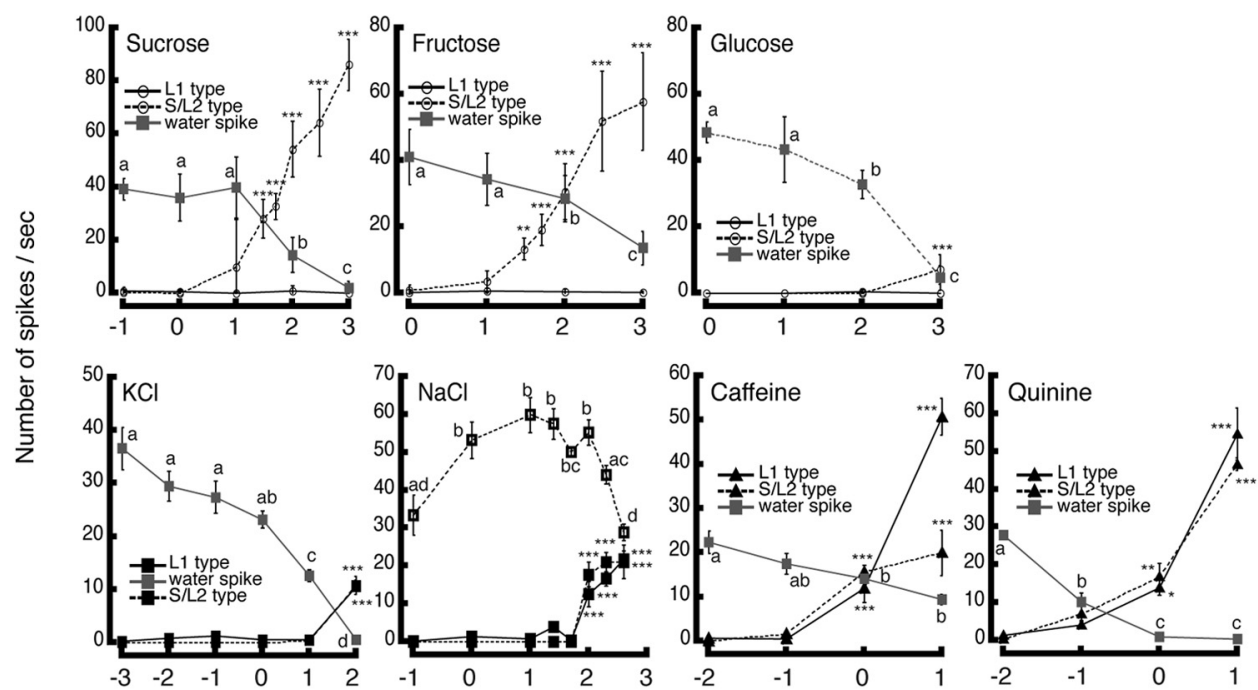

- $L 1$ type
-S/L2 type (low spike)
-S/L2 type (high spike)

Concentration $(\log 10(\mathrm{mM}))$

Figure 4. Typical recordings of $\mathrm{L} 1$ (left column) and $\mathrm{L} 2$ or $S$ sensilla (right column) in response to $\boldsymbol{A}, 100 \mathrm{~mm}$ sucrose; $\boldsymbol{B}, 100 \mathrm{~mm}$ fructose; $\boldsymbol{C}, 100 \mathrm{~mm}$ glucose; $\boldsymbol{D}, 1 \mathrm{~mm} \mathrm{KCl} ; \boldsymbol{E}, 100 \mathrm{~mm} \mathrm{KCl} ; \boldsymbol{F}, 50 \mathrm{~mm}$ $\mathrm{NaCl}, \mathbf{G}, 200 \mathrm{~mm} \mathrm{NaCl}, \boldsymbol{H}, 10 \mathrm{~mm}$ caffeine, and $\boldsymbol{I}, 0.1 \mathrm{~mm}$ quinine. Gray squares, open circles, open squares, closed squares, and triangles indicate water, sugar, salt (low amplitude-spikes), salt (high amplitude-spikes), and bitter responses, respectively. J, Dose dependency of responses to sucrose, fructose, glucose, $\mathrm{KCl}, \mathrm{NaCl}$, caffeine, and quinine. (mean $\pm \mathrm{SD}$ spike frequencies; $n=5-50$ for sucrose, $n=6-21$ for fructose, $n=7-13$ for glucose, $n=11-60 \mathrm{for} \mathrm{KCl}, n=6-66$ for NaCl, $n=5-33$ for caffeine, and $n=6-15$ for quinine). Different letters (a-d) indicate significant differences of water spikes and salt spikes (low amplitude) in L2 and S sensilla among concentrations (Tukey-Kramer test, $p<0.05$ ). ${ }^{*} p<0.01,{ }^{* *} p<0.001,{ }^{* * *} p<0.0001$ versus $0.1 \mathrm{~mm}$ sucrose, $1 \mathrm{~mm}$ fructose, $1 \mathrm{~mm}$ glucose, $0.01 \mathrm{~mm} \mathrm{KCl}, 0.1 \mathrm{~mm} \mathrm{NaCl}, 0.01 \mathrm{~mm}$ caffeine, and $0.01 \mathrm{~mm}$ quinine, respectively. 
A

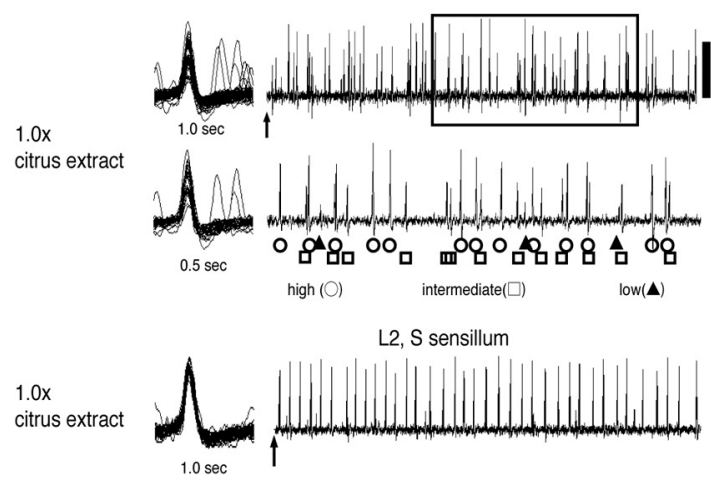

L1 sensillum

$0.1 \mathrm{x}$

citrus extract

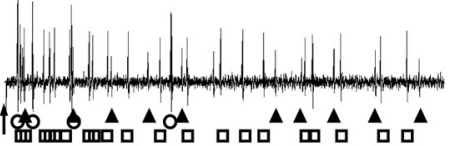

$0.01 x$

citrus extract

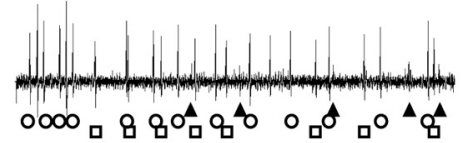

$0.001 x$

citrus extract

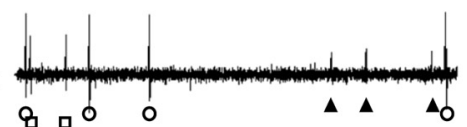

B
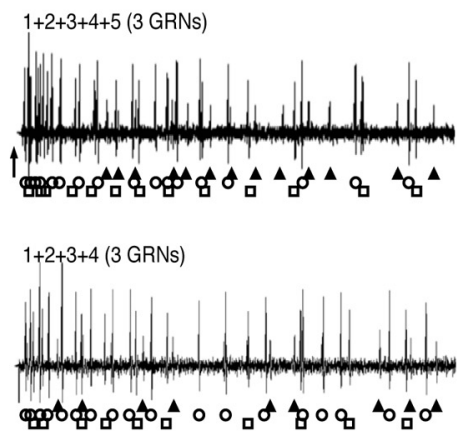

$1+2+4$ (3 GRNs)

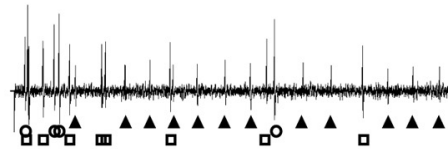

1+3+4 (3 GRNs)

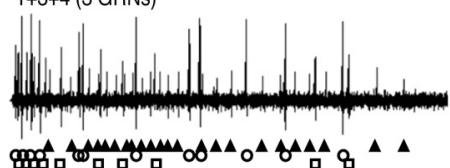

C

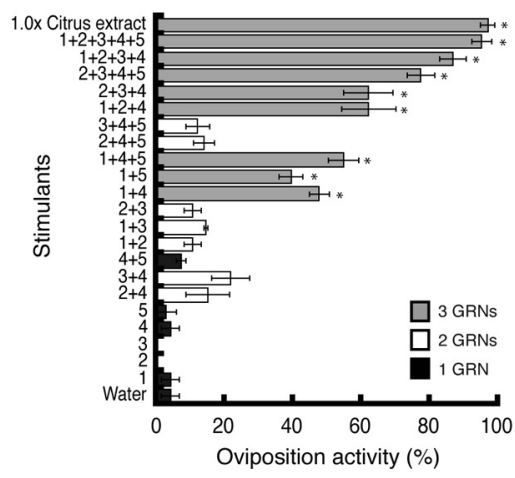

1: Synephrine

3: 5-Hydroxy-N $\omega$-methyltryptamine

4. chiro-Inositol
$2+3+4+5$ (3 GRNs)

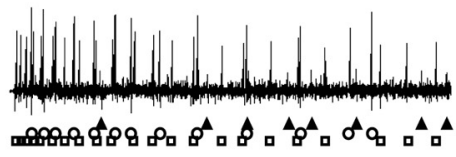

1+4+5 (3 GRNs)

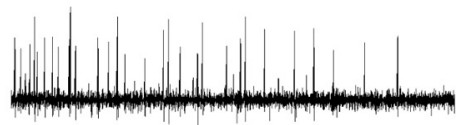

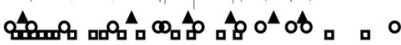

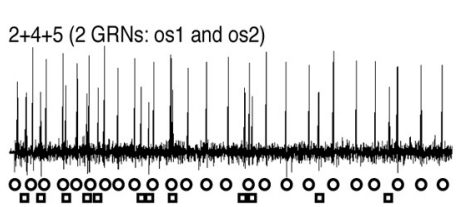

3+4+5 (2 GRNs: os2 and os3)

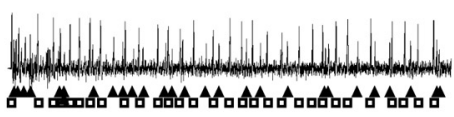

1: Synephrine

3: 5-Hydroxy-N $\omega$-methyltryptamine

4: chiro-Inositol

5: Nariturin

O os 1

प os2
\ os3

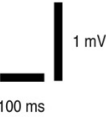

D

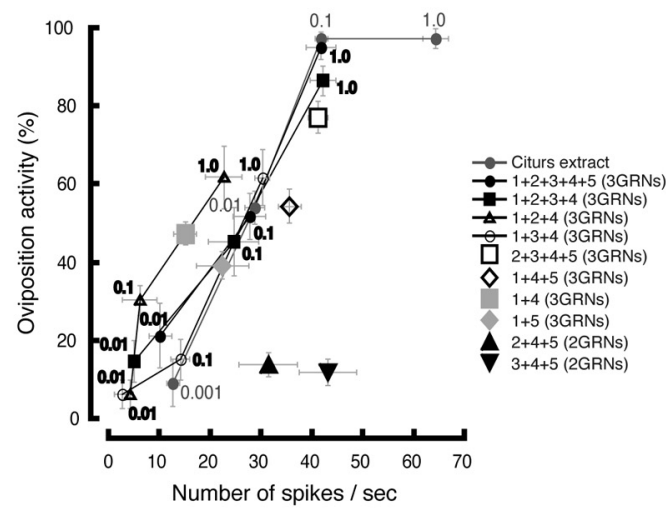

Figure 5. Electrophysiological and oviposition responses to whole-leaf citrus extract and mixtures of oviposition stimulants. $A$, Typical response to $1.0 \times$ citrus extract (left). Scale bar, $1.0 \mathrm{mV}$. Arrows indicate the onset of stimulation. The first trace showed impulses during the first second after stimulation; the 0.5 s trace below it expands the boxed region in the $1.0 \mathrm{~s}$ trace. Circles, squares, and triangles indicate high, intermediate, and low spikes, respectively. The $0.1-0.001 \times$ citrus extracts also elicited three types of spikes in L1 sensilla during the first second of stimulation (right). $B$, Typical responses of $L 1$ sensilla to mixtures of oviposition stimulants. The mixtures of oviposition stimulants were based on the estimated concentrations of each compound in whole-leaf extracts of C. unshiu (see Fig. 2). The five oviposition stimulants were numbered as follows: synephrine, 1; stachydrine, 2; 5-hydroxy-N $\omega$-methyltryptamine, 3; chiro-inositol, 4; and narirutin, 5 . Circles, squares, and triangles indicate oviposition spike 1 (os1), os2, and os3, respectively. C, Assay of oviposition behavior (oviposition activities; $n=9$ for $1.0 \times$ citrus extract, $n=5$ for (Figurelegend continues.) 
Table 1. Number of spikes (mean $\pm \mathrm{SE}$ ) elicited by citrus extract in L1 sensilla

\begin{tabular}{|c|c|c|c|c|}
\hline \multirow[b]{2}{*}{ Stimulants } & \multicolumn{4}{|l|}{ Dilution ratio } \\
\hline & 1.0 & 0.1 & 0.01 & 0.001 \\
\hline Total & $64.2 \pm 2.4^{a}$ & $41.7 \pm 1.3^{b}$ & $28.6 \pm 1.9^{c}$ & $12.5 \pm 1.3^{d}$ \\
\hline High & $26.9 \pm 3.2^{a}$ & $14.5 \pm 1.9^{b}$ & $9.5 \pm 1.3^{b}$ & $4.8 \pm 0.8^{c}$ \\
\hline Intermediate & $14.1 \pm 2.0^{a}$ & $11.8 \pm 1.7^{a}$ & $8.4 \pm 2.0^{a, b}$ & $2.9 \pm 0.8^{b}$ \\
\hline Low & $23.1 \pm 2.1^{a}$ & $14.9 \pm 1.8^{b}$ & $11.0 \pm 1.7^{b, c}$ & $4.8 \pm 0.6^{c}$ \\
\hline
\end{tabular}

$\overline{a, b, c, d}$ Different letters $(a-d)$ indicate significant differences in total spikes or in each type of spike by Tukey-Kramer test $(p<0.05)$.

Each value represents the mean \pm SE in number of spikes ( $n=11$ for $1.0 \times$ citrus extract, $n=20$ for $0.1 \times$ citrus extract, $n=15$ for $0.01 \times$ citrus extract, and $n=19$ for $0.001 \times$ citrus extract).

Table 2. Number of spikes (mean $\pm \mathrm{SE}$ ) elicited by citrus extract and mixtures of oviposition stimulants in L1 sensilla

\begin{tabular}{lclll}
\hline \multicolumn{5}{c}{ Dilution ratio } \\
Stimulants & 1.0 & 0.1 & 0.01 & 0.001 \\
Citrus extract & $64.2 \pm 2.4^{a}$ & $41.7 \pm 1.3^{b}$ & $28.6 \pm 1.9^{c}$ & $12.5 \pm 1.3^{d, e}$ \\
$1+2+3+4+5$ & $41.6 \pm 2.9^{b}$ & $27.6 \pm 3.2^{c}$ & $10.0 \pm 2.3^{d, e}$ & - \\
$1+2+3+4$ & $42 \pm 2.5^{b}$ & $24.4 \pm 4.9^{c}$ & $5.0 \pm 0.9^{d}$ & - \\
$1+2+4$ & $22.5 \pm 1.5^{c, f}$ & $6.0 \pm 1.8^{d, e}$ & $4.2 \pm 1.5^{d}$ & - \\
$1+3+4$ & $30.1 \pm 3.5^{c}$ & $14.0 \pm 3.4^{e, f}$ & $2.5 \pm 0.5^{d}$ & - \\
$2+3+4+5$ & $41.0 \pm 2.0^{b}$ & - & - & - \\
$1+4+5$ & $35.4 \pm 2.2^{b, c}$ & - & - & - \\
$1+4$ & $14.9 \pm 2.2^{e, f}$ & - & - & - \\
$1+5$ & $22.3 \pm 5.1^{c, f}$ & - & - & - \\
$2+4+5$ & $31.3 \pm 5.8^{c}$ & - & - & - \\
$3+4+5$ & $43.0 \pm 5.6^{b}$ & - & - & - \\
\hline
\end{tabular}

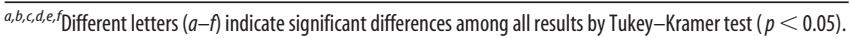
1, Synephrine; 2, stachydrine; 3, 5-hydroxy-N $\omega$-methyltryptamine; 4, chiro-inositol; 5. narirutin. "-" indicates no recordings. Each value represents the mean \pm SE in number of spikes $(n=7-40)$

stimulants eliciting three types of spikes; $r_{(15)}=0.9325, t=$ $\left.10.0024, p=4.98099 \times 10^{-8}\right)$. On the other hand, mixtures of oviposition stimulants eliciting two types of spikes $(2+4+5$ and $3+4+5)$ showed low oviposition activities $(2+4+5$ and mixtures of $1.0 \times$ mixtures of three stimulants; $F_{(3,39)}=18.793$, $p<0.0001$, and $3+4+5$ and mixtures of $1.0 \times$ mixtures of 4 or 5 stimulants; $\left.F_{(3,38)}=88.124, p<0.0001\right)$, even though they elicited as many spikes as would induce oviposition by some mixtures that elicited three types of spikes $(2+4+5$ and $1.0 \times$ mixtures of three stimulants; $F_{(3,93)}=2.398, p=0.07292$, and

$\leftarrow$

(Figure legend continued.) $1+2+3+4+5, n=10$ for $1+2+3+4, n=15$ for $2+$ $3+4+5, n=7$ for $2+3+4, n=9$ for $1+2+4, n=12$ for $3+4+5, n=12$ for $2+$ $4+5, n=15$ for $1+4+5, n=12$ for $1+5, n=20$ for $1+4, n=3$ for $2+3, n=3$ for $1+3, n=3$ for $1+2, n=4$ for $3+4, n=4$ for $2+4, n=5$ for $5, n=7$ for $4, n=4$ for $3, n=4$ for $2, n=7$ for 1 , and $n=7$ for water). Each value represents the mean \pm SE of $3-20$ independent determinations, each of which was the average of 7-10 individuals. The gray, white, and black bars indicate whether three, two, or one GRN was fired by each solution, except for water. ${ }^{*} p<0.0001$ versus oviposition activity induced by water alone (Tukey-Kramer test; $\left.F_{(22,157)}=48.947\right)$. D, Correlation between number of spikes and oviposition activity. Gray circles, closed circles, squares, triangles, open circles, open square, open diamond, gray square, gray diamond, closed triangle, and closed triangle (downward) indicate citrus extract and mixtures of $1+2+3+4+5,1+2+3+4,1+2+4,1+3+4,2+3+4+5,1+$ $4+5,1+4,1+5,2+4+5$, and $3+4+5$, respectively. Each value represents oviposition activity on the vertical axis (mean $\pm \operatorname{SE} n=4-11$ for citrus extract, $n=3-5$ for $1+2+3+$ $4+5, n=3-10$ for $1+2+3+4, n=3-7$ for $1+2+4, n=3-9$ for $1+3+4, n=$ 15 for $2+3+4+5, n=15$ for $1+4+5, n=20$ for $1+4, n=12$ for $1+5, n=12$ for $2+4+5$, and $n=12$ for $3+4+5$ ) and the number of spikes on the horizontal axis (mean \pm SE $n=12-20$ for citrus extract, $n=17-30$ for $1+2+3+4+5, n=7-26$ for $1+2+3+4, n=12-21$ for $1+2+4, n=11-28$ for $1+3+4, n=40$ for $2+3+$ $4+5, n=10$ for $1+4+5, n=13$ for $1+4, n=12$ for $1+5, n=40$ for $2+3+4$, and $n=7$ for $3+4+5$ ). The results of post hoc multiple comparisons of these data are described in Tables 2 and 3 , respectively.
Table 3. Oviposition activities (mean \pm SE) elicited by citrus extract and mixtures of oviposition stimulants

\begin{tabular}{lllll}
\hline \multicolumn{5}{c}{ Dilution ratio } \\
Stimulants & 1.0 & 0.1 & 0.01 & 0.001 \\
Citrus extract & $97.5 \pm 2.5^{a}$ & $97.5 \pm 1.7^{a}$ & $54.2^{c} \pm 4.2^{c}$ & $9.4 \pm 6.0^{d}$ \\
$1+2+3+4+5$ & $95.1 \pm 3.0^{a}$ & $52.0 \pm 5.9^{c, e}$ & $21.5 \pm 8.3^{d, e}$ & - \\
$1+2+3+4$ & $86.7 \pm 3.9^{a, b}$ & $45.5 \pm 8.8^{c, e}$ & $14.8 \pm 5.3^{d, e}$ & - \\
$1+2+4$ & $61.9 \pm 7.2^{c}$ & $15.3 \pm 5.2^{d, e}$ & $6.5 \pm 3.6^{d}$ & - \\
$1+3+4$ & $62.0 \pm 7.9^{c}$ & $30.5 \pm 3.7^{d, e}$ & $6.5 \pm 3.6^{d}$ & - \\
$2+3+4+5$ & $77.4 \pm 4.0^{b}$ & - & - & - \\
$1+4+5$ & $54.6 \pm 4.5^{c}$ & - & - & - \\
$1+4$ & $47.6 \pm 3.0^{c, e}$ & - & - & - \\
$1+5$ & $39.4 \pm 3.5^{c, e}$ & - & - & - \\
$2+4+5$ & $13.9 \pm 3.1^{d}$ & - & - & - \\
$3+4+5$ & $12.1 \pm 3.4^{d}$ & - & - & - \\
\hline
\end{tabular}

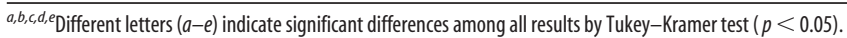
1, Synephrine; 2, stachydrine; 3, 5-hydroxy-N $\omega$-methyltryptamine; 4, chiro-inositol, 5, narirutin. " -" indicates no data. Each value represents the mean \pm SE of oviposition activity $(n=3-20)$.
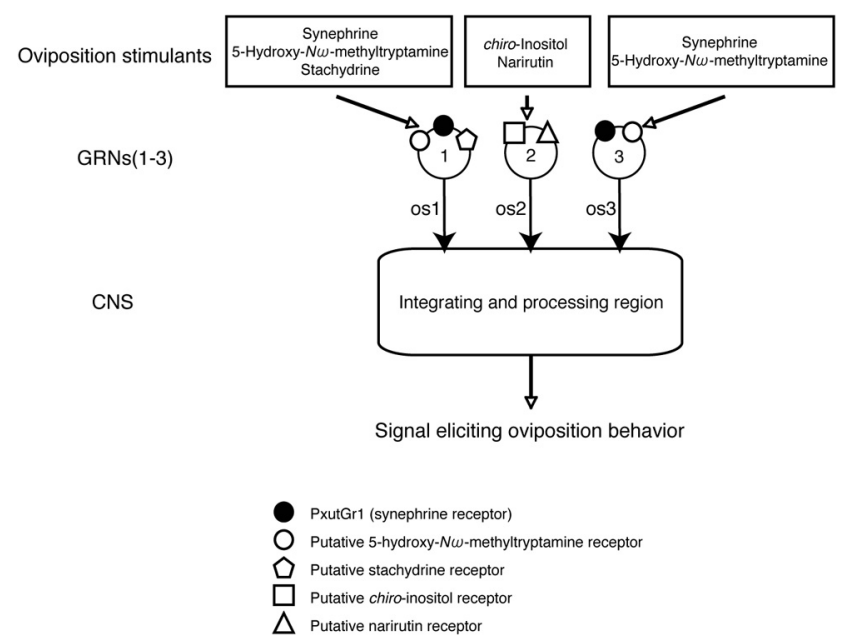

Figure 6. Model of the neural pathway modulating oviposition behavior elicited by oviposition stimulants.

$3+4+5$ and $1.0 \times$ mixtures of 4 or 5 stimulants; $F_{(3,98)}=0.0341$, $p=0.99148)$. These results suggest that both quality (three types of spike) and quantity (a critical level of the frequency of three types of spikes) are required to induce oviposition behavior.

\section{Discussion}

We found that P. xuthus had three types of sensilla-L1, L2, and $\mathrm{S}$ - with different sensory functions via a systematic electrophysiological analysis of sensilla on the fifth tarsomere of forelegs (Figs. 1, 2, 4). The L1 sensilla responded preferentially to five oviposition stimulants: synephrine, stachydrine, 5-hydroxy- $N \omega$ methyltryptamine, chiro-inositol, and narirutin. Furthermore, the responses in L1 sensilla showed a consistent correlation between the spike patterns elicited by some mixtures of stimulants and the oviposition-inducing activities of these mixtures (Fig. $5 D)$. In contrast, L2 and S sensilla responded to three oviposition stimulants and to general tastants (Figs. 2, 4). Among the three oviposition stimulants, stachydrine and 5-hydroxy$N \omega$-methyltryptamine elicited spikes at concentrations comparable to those found in C. unshiu leaves (Fig. 2I), but the mixture of these stimulants elicited no oviposition activity (Fig. 5C). These results suggest that L2 and S sensilla do not participate directly in eliciting the oviposition behavior, although L2 and S sensilla might have some physiological role because they possess 
GRN(s) that respond to stimulants and to the citrus extract (Fig. $5 A$ ). We therefore postulate that chemosensory neurons in the L1 sensillum are mainly involved in triggering the oviposition behavior in the females.

In L1 sensilla, five stimulants elicited three types of spikes os1, os2, and os 3 - either alone or as a combination of os 1 and os3 (Fig. 2). The os1, os2, and os3 elicited by various mixtures of stimulants showed doublet spikes with the same amplitude and shape as spikes elicited by individual stimulants (Fig. 3). Because these three types of spikes originated from discrete three GRNs and the combinations of oviposition stimulants that elicited the same-amplitude spikes did not elicit the doublet spikes, the oviposition stimulants that elicited spikes with the same amplitude are probably detected by the same GRN. The citrus extract also elicited at least three types of spikes (Fig. 5A), suggesting that the spikes are the same as those elicited by the five oviposition stimulants. These results suggest that specific three GRNs encoding the multiple oviposition stimulants exist in the gustatory sensing system of $P$. xuthus.

In oviposition behavioral assays, the oviposition activities induced by the mixtures of oviposition stimulants that elicited three types of spikes, os 1, os2, and os 3 were almost comparable to that of tenfold diluted citrus extract (Fig. 5D). Conversely, the mixtures eliciting one or two types of spikes induced low oviposition activities (Fig. 5C,D). Considering the oviposition and the electrophysiological data together, we propose two conditions that must be met for a chemical mixture to induce the oviposition behavior. First, the simultaneous occurrence of multiple spikesos1, os2, and os3 - in three discrete GRNs of L1 sensilla should be necessary to induce oviposition behavior. For example, mixtures of the two compounds, synephrine and either chiro-inositol or narirutin, elicited higher oviposition activity than any other twocompound mixtures (Fig. 5C). Synephrine was the sole stimulant that elicited both os 1 and os3 spikes simultaneously in concentrations equivalent to those estimated in whole $C$. unshiu leaves (Fig. 2I). Because chiro-inositol and narirutin evoked the os 2 spike, the two mixtures elicited the os1, os2, and os3 spikes. Second, the frequency of all three types of spikes should be greater than a certain level to trigger sufficient synergistic effects for oviposition activity, because a clear correlation was observed between the frequency of spikes and oviposition activity elicited only by the mixtures of stimulants elicited three types of spikes (Fig. 5D). We propose that oviposition behavior can be elicited only when the three GRNs in the L1 sensilla responded simultaneously to oviposition stimulants in frequency of stimuli above each of certain levels.

Our data indicated that $P$. xuthus would use three GRNs to encode the chemical signature of multiple oviposition stimulants, although the five oviposition stimulants of $P$. xuthus have little structural similarity. These three neural pathways possibly represent three new modalities for regulating single behavior, oviposition, in addition to the four taste modalities generally described in insects, namely sweet, bitter, salt and water. A classification of GRNs was established in Drosophila melanogaster and Phormia regina: GRNs have been classified into water, sugar, salt, and bitter cells (Dethier and Goldrich-Rachman, 1976; Rodrigues and Siddiqi, 1978; Fujishiro et al., 1984; Wieczorek and Wolff, 1989; Meunier et al., 2003). Therefore, multiple sugars and bitter compounds seem to be perceived by individual GRNs. Previous reports indicated that $\mathrm{Z}$-7-tricosene, an inhibitory sex pheromone of Drosophila males, was recognized by the Gr66aexpressing neuron (bitter cells) and induced aversive responses in a feeding test, and showed the same $\mathrm{Ca}^{2+}$-response as bitter com- pounds in Gr66a-expressing neurons of the CNS(Lacaille et al., 2007; Inoshita et al., 2011). These findings indicated that different chemicals processed by the same neural pathway could induce similar behavioral responses.

We found that the electrophysiological response to a given oviposition stimulant varied among L1 sensilla (Fig. $2 J$ ). Some L1 sensilla exhibited only one or two types of spikes when stimulated by citrus extract or mixtures of oviposition stimulants that elicited os 1, os2, and os3 (data not shown). These results suggest that L1 sensilla house a different number of GRNs that respond to each oviposition stimulant and that oviposition behavior is induced by the total response to different combinations of the three GRNs in a population of L1 sensilla. The different responses to oviposition stimulants among L1 sensilla might also result from distinct expressions of receptors that perceive oviposition stimulants among GRNs, as known in Drosophila gustatory receptors (Weiss et al., 2011). To classify sensilla based on response spectra, we have tried to make a distribution map of sensilla by numbering them, but had no success, because the locations of these sensilla on the tarsomere varied among individuals.

We have recently identified a gustatory receptor PxutGr1 that is specific for synephrine and is expressed in the foreleg tarsi of $P$. xuthus (Ozaki et al., 2011). Females injected with PxutGr1dsRNA exhibited reduced responses to synephrine and reduced oviposition activity induced by a mixture of synephrine and chiro-inositol. Because synephrine elicits the os 1 and os 3 spikes, we believe that the PxutGr1 receptor may be expressed by two GRNs. Based on the present findings, we propose a model for the neural pathway involved in modulation of oviposition behavior by the five oviposition stimulants (Fig. 6). In constructing the model, we assumed that the butterfly $P$. xuthus uses the CNS region to receive and process signals from GRN in contact chemosensilla as reported in Diptera and Lepidoptera (Marella et al., 2006; Thorne et al., 2004; Jørgensen et al., 2006; Kvello et al., 2006; Koganezawa et al., 2010). The PxutGr1 appears to be expressed in GRN1 and GRN3, because synephrine elicits os1 and os3. Likewise, putative receptors for the other four oviposition stimulants may be expressed in three GRNs depending on encoding pattern of them. In other words, PxutGr1 and the putative receptors for 5-hydroxy- $N \omega$-methyltryptamine and stachydrine become the common signature for GRN1, chiro-inositol and narirutin are the common signature for GRN2, and synephrine and 5-hydroxy- $N \omega$-methyltryptamine are the signature for GRN3. The three GRNs may project into the CNS. These signals transduced from the 3 GRNs may be then integrated and processed in the CNS to give rise to signals to induce oviposition behavior.

This study showed that $P$. xuthus could use three GRNs that encode the taste signals of multiple oviposition stimulants that regulate the oviposition behavior. Our findings provide a novel mechanism to modulate butterfly oviposition behavior based on multiple taste signals and represent the first step toward elucidating the perception mechanism underlying host plant selection by Papilionidae butterflies.

\section{References}

Calabrò ML, Tommasini S, Donato P, Stancanelli R, Raneri D, Catania S, Costa C, Villari V, Ficarra P, Ficarra R (2005) The rutin/betacyclodextrin interactions in fully aqueous solution: spectroscopic studies and biological assays. J Pharm Biomed Anal 36:1019-1027. CrossRef Medline

Calas D, Thiéry D, Marion-Poll F (2006) 20-Hydroxyecdysone deters oviposition and larval feeding in the European grapevine moth, Lobesia botrana. J Chem Ecol 32:2443-2454. CrossRef Medline

Carter M, Feeny P, Haribal M (1999) An oviposition stimulant for spice- 
bush swallowtail butterfly, Papilio troilus, from leaves of Sassafras albidum. J Chem Ecol 25:1233-1245. CrossRef

Dethier VG, Goldrich-Rachman N (1976) Anesthetic stimulation of insect water receptors. Proc Natl Acad Sci U S A 73:3315-3319. CrossRef Medline

Evans DR, Mellon D Jr (1962) Electrophysiological studies of a water receptor associated with the taste sensilla of the blowfly. J Gen Physiol 45:487500. CrossRef Medline

Feeny P, Rosenberry L, Carter M (1983) Chemical aspects of oviposition behavior in butterflies. In: Herbivorous insects: host-seeking behavior and mechanisms (Ahmad S, ed), pp 26-76. New York: Academic.

Feeny P, Sachdev K, Rosenberry L, Carter M (1988) Luteolin 7-O- (6“malonyl)- $\beta$-D- glucoside and trans-chlorogenic acid: oviposition stimulants for the black swallowtail butterfly. Phytochem 27:3439-3448. CrossRef

Fujishiro N, Kijima H, Morita H (1984) Impulse frequency and actionpotential amplitude in labellar chemosensory neurons of Drosophila melanogaster. J Insect Physiol 30:317-325. CrossRef

Hiroi M, Marion-Poll F, Tanimura T (2002) Differentiated response to sugars among labellar chemosensilla in Drosophila. Zool Sci 19:1009-1018. CrossRef Medline

Hiroi M, Meunier N, Marion-Poll F, Tanimura T (2004) Two antagonistic gustatory receptor neurons responding to sweet-salty and bitter taste in Drosophila. J Neurobiol 61:333-342. CrossRef Medline

Hodgson ES, Lettvin JY, Roeder KD (1955) Physiology of a primary chemoreceptor unit. Science 122:417-418. CrossRef Medline

Honda K (1986) Flavanone glycosides as oviposition stimulants in a papilionid butterfly, Papilio protenor. J Chem Ecol 12:1999-2010. CrossRef

Honda K (1990) Identification of host-plant chemicals stimulating oviposition by swallowtail butterfly, Papilio protenor. J Chem Ecol 16:325-337. CrossRef

Honda K (1995) Chemical basis of differential oviposition by lepidopterous insects. Arch Insect Biochem Physiol 30:1-23. CrossRef

Ichinose T, Honda H (1978) Ovipositional behavior of Papilio protenor demetrius cramer and the factors involved in its host plants. Appl Entmol Zool 13:103-114.

Inoshita T, Martin JR, Marion-Poll F, Ferveur JF (2011) Peripheral, central and behavioral responses to the cuticular pheromone bouquet in Drosophila melanogaster males. PLoS One 6:e19770. CrossRef Medline

Jørgensen K, Kvello P, Almaas TJ, Mustaparta H (2006) Two closely located areas in the suboesophageal ganglion and the tritocerebrum receive projections of gustatory receptor neurons located on the antennae and the proboscis in the moth Heliothis virescens. J Comp Neurol 496:121-134. CrossRef Medline

Kelber A (1999) Ovipositing butterflies use a red receptor to see green. J Exp Biol 202:2619-2630. Medline

Koganezawa M, Haba D, Matsuo T, Yamamoto D (2010) The shaping of male courtship posture by lateralized gustatory inputs to male-specific interneurons. Curr Biol 20:1-8. CrossRef Medline

Kvello P, Almaas TJ, Mustaparta H (2006) A confined taste area in a lepidopteran brain. Arthropod Struct Dev 35:35-45. CrossRef Medline

Lacaille F, Hiroi M, Twele R, Inoshita T, Umemoto D, Manière G, MarionPoll F, Ozaki M, Francke W, Cobb M, Everaerts C, Tanimura T, Ferveur JF (2007) An inhibitory sex pheromone tastes bitter for Drosophila males. PLoS One 2:e661. CrossRef Medline
Majumdar S, Srirangam R (2009) Solubility, stability, physicochemical characteristics and in vitro ocular tissue permeability of hesperidin: a natural bioflavonoid. Pharm Res 26:1217-1225. CrossRef Medline

Marella S, Fischler W, Kong P, Asgarian S, Rueckert E, Scott K (2006) Imaging taste responses in the fly brain reveals a functional map of taste category and behavior. Neuron 49:285-295. CrossRef Medline

Marion-Poll F (1995) Object-oriented approach to fast display of electrophysiological data under MS-windows. J Neurosci Methods 63:197-204. CrossRef Medline

Marion-Poll F (1996) Display and analyses of electrophysiological data under Windows. Entomol Exp Appl 80:116-119. CrossRef

Marion-Poll F, van der Pers J (1996) Un-filtered recordings from insect taste sensilla. Entomol Exp Appl 80:113-115. CrossRef

Meunier N, Marion-Poll F, Rospars JP, Tanimura T (2003) Peripheral coding of bitter taste in Drosophila. J Neurobiol 56:139-152. CrossRef Medline

Murakami T (2003) Studies on the relationships between host-plant acceptability and plant constituents in host selection by a swallowtail butterfly, Papilio polytes. J Grad Sch Biosp Sci 42:58-59.

Nakayama T, Honda K, Omura H, Hayashi N (2003) Oviposition stimulants for the tropical swallowtail butterfly, Papilio polytes, feeding on a rutaceous plant, Toddalia asiatica. J Chem Ecol 29:1621-1634. CrossRef Medline

Nishida R, Ohsugi T, Kokubo S, Fukami H (1987) Oviposition stimulants of a citrus-feeding swallowtail butterfly, Papilio xuthus, L. Experientia 43: 342-344. CrossRef

Ohsugi T, Nishida R, Fukami H (1991) Multi-component system of oviposition stimulants for a Rutaceae-feeding swallowtail butterfly, Papilio xuthus (Lepidoptera: Papilionidae). Appl Entmol Zool 26:29-40.

Ono H, Nishida R, Kawahara Y (2000a) A dihydroxy- $\gamma$-lactone as an oviposition stimulant for the swallowtail butterfly, Papilio bianor, from the Rutaceous plant, Orixa japonica. Biosci Biotechnol Bioch 64:1970-1973. CrossRef

Ono H, Nishida R, Kuwahara Y (2000b) Oviposition stimulant for a Rutaceae-feeding swallowtail butterfly, Papilio bianor (Lepidoptera: Papilionidae): Hydroxycinnamic acid derivative from Orixa japonica. Appl Entmol Zool 35:119-123. CrossRef

Ozaki K, Ryuda M, Yamada A, Utoguchi A, Ishimoto H, Calas D, Marion-Poll F, Tanimura T, Yoshikawa H (2011) A gustatory receptor involved in host-plant recognition for oviposition of the butterfly, Papilio xuthus. Nat Commun 2:542. CrossRef Medline

Rausher MD (1978) Search image for leaf shape in a butterfly. Science 2:1071-1073.

Rodrigues V, Siddiqi O (1978) Genetic analysis of chemosensory pathway. Proc Indian Acad Sci Sect B 87:147-160.

Thorne N, Chromey C, Bray S, Amrein H (2004) Taste perception and coding in Drosophila. Curr Biol 14:1065-1079. CrossRef Medline

Weiss LA, Dahanukar A, Kwon JY, Banerjee D, Carlson JR (2011) The molecular and cellular basis of bitter taste in Drosophila. Neuron 69:258-272. CrossRef Medline

Wieczorek H, Wolff G (1989) The labellar sugar receptor of Drosophila. J Comp Physiol A Neuroethol Sens Neural Behav Physiol 164:825-834. CrossRef 